\title{
First report of bean leafroll virus (BLRV) naturally infecting common and bitter vetch and alfalfa in Greece
}

\author{
${\text { Leonidas } \text { Lotos }^{1}(\mathbb{D} \cdot \text { loannis Tsialtas }}^{2} \cdot$ Nikolaos Katis $^{1} \cdot$ Varvara Maliogka $^{1}$
}

Received: 7 February 2021 / Accepted: 26 February 2021 / Published online: 4 March 2021

(c) Società Italiana di Patologia Vegetale (S.I.Pa.V.) 2021

Keywords BLRV $\cdot$ Luteovirus $\cdot$ Fabaceae viruses $\cdot$ Bean leafroll virus

Common (Vicia sativa L. subsp. sativa) and bitter (Vicia ervilia (L.) Willd.) vetch and alfalfa (Medicago sativa $\mathrm{L}$. subsp. sativa) are Fabaceae species grown in Greece as winter crops for hay or seed used as feed. During spring 2011, virus-like symptoms were observed in common and bitter vetch plants in the Aristotle University of Thessaloniki Farm $\left(40^{\circ} 32^{\prime} \mathrm{N} 22^{\circ} 59^{\prime} \mathrm{E}\right)$. Common vetch plants exhibited leaf yellowing and later on tip necrosis, thus giving the affected plants a burnt-like appearance. Reduction in pod numbers exceeded $60 \%$. In bitter vetch, mild leaflet reddening symptoms appeared later in the growing season, while reduction in pod number was negligible. In alfalfa, viruslike symptoms were observed during the summer of 2011 in field crops grown in Elefthero-Grevena $\left(40^{\circ} 09^{\prime} \mathrm{N} 21^{\circ} 25^{\prime} \mathrm{E}\right)$. The initial symptom was interveinal chlorosis of the upper leaves, which subsequently turned into total chlorosis and finally, the leaves also developed top and peripheral reddening. Disease symptoms were consistent with a luteovirid infection and more specifically with symptoms caused by bean leafroll virus (BLRV). Two samples from diseased plants as well as two asymptomatic controls were collected for each plant species. Total RNA was extracted from the samples (Maliogka et al. 2015) and a BLRV specific RTPCR was carried out, as described by Ortiz et al. (2005). The expected $391 \mathrm{bp}$ amplicon was obtained from all the symptomatic plants but not from the asymptomatic controls. The amplicon sequence from one sample of each plant species was obtained and deposited to ENA, with accession numbers

Leonidas Lotos

1lotos@agro.auth.gr

1 School of Agriculture, Laboratory of Plant Pathology, Aristotle University of Thessaloniki, 54124 Thessaloniki, Greece

2 School of Agriculture, Laboratory of Agronomy, Aristotle University of Thessaloniki, 54124 Thessaloniki, Greece
HE601635, HE601636, HE601637 for BLRV isolates from common vetch, bitter vetch and alfalfa, respectively. BLASTn analysis revealed 93-100\% identity with BLRV isolates. BLRV is a common pathogen of grain and forage legumes with a worldwide distribution and has been detected in lentils in Greece (Chatzivassiliou et al. 2016). However, to our knowledge, this is the first report of natural infection of common vetch, bitter vetch and alfalfa with BLRV in Greece.

Funding No funding was received for conducting this study.

\section{Declarations}

Conflict of interest The authors have no conflicts of interest to declare that are relevant to the content of this article.

\section{References}

Chatzivassiliou E, Giakountis A, Kumari S, Makkouk K (2016) Viruses affecting lentil (Lens culinaris Medik.) in Greece; incidence and genetic variability of bean leafroll virus and pea enation mosaic virus. Phytopathol Mediterr, 55(2), 239-252

Maliogka VI, Olmos A, Pappi PG, Lotos L, Efthimiou K, Grammatikaki G, Candresse T, Katis NI, Avgelis AD (2015) A novel grapevine badnavirus is associated with the Roditis leaf discoloration disease. Virus Res 203:47-55

Ortiz V, Castro S, Romero J (2005) Optimization of RT-PCR for the detection of bean leaf roll virus in plant hosts and insect vectors. J Phytopathol 153(2):68-72

Publisher's Note Springer Nature remains neutral with regard to jurisdictional claims in published maps and institutional affiliations. 